\title{
Lateral Entorhinal Modulation of Piriform Cortical Activity and Fine Odor Discrimination
}

\author{
Julie Chapuis, ${ }^{1,2 \star}$ Yaniv Cohen, ${ }^{1,2 \star}$ Xiaobin He, ${ }^{3,5 *}$ Zhijan Zhang, ${ }^{3,4,6}$ Sen Jin, ${ }^{3}$ Fuqiang Xu,,${ }^{3,4,5}$ and Donald A. Wilson ${ }^{1,2,4}$ \\ ${ }^{1}$ Emotional Brain Institute, Nathan Kline Institute for Psychiatric Research, Orangeburg, New York 10962, ${ }^{2}$ Child and Adolescent Psychiatry, New York \\ University Langone School of Medicine, New York, New York 10016, ${ }^{3}$ State Key Laboratory of Magnetic Resonance and Atomic and Molecular Physics, \\ Wuhan Institute of Physics and Mathematics, the Chinese Academy of Sciences, Wuhan 430071, China, ${ }^{4}$ Wuhan National Laboratory for Optoelectronics, \\ Wuhan 430074, China, ${ }^{5}$ University of Chinese Academy of Sciences, Beijing, 100049, China, and ${ }^{6}$ College of Life Science and Technology, Huazhong \\ University of Science and Technology, Wuhan 430074, China
}

The lateral entorhinal cortex (LEC) receives direct input from olfactory bulb mitral cells and piriform cortical pyramidal cells and is the gateway for olfactory input to the hippocampus. However, the LEC also projects back to the piriform cortex and olfactory bulb. Activity in the LEC is shaped by input from the perirhinal cortices, hippocampus, and amygdala, and thus could provide a rich contextual modulation of cortical odor processing. The present study further explored LEC feedback to anterior piriform cortex by examining how LEC top-down input modulates anterior piriform cortex odor evoked activity in rats. Retrograde viral tracing confirmed rich LEC projections to both the olfactory bulb and piriform cortices. In anesthetized rats, reversible lesions of the ipsilateral LEC increased anterior piriform cortical single-unit spontaneous activity. In awake animals performing an odor discrimination task, unilateral LEC reversible lesions enhanced ipsilateral piriform cortical local field potential oscillations during odor sampling, with minimal impact on contralateral activity. Bilateral LEC reversible lesions impaired discrimination performance on a well learned, difficult odor discrimination task, but had no impact on a well learned simple odor discrimination task. The simple discrimination task was impaired by bilateral reversible lesions of the anterior piriform cortex. Given the known function of LEC in working memory and multisensory integration, these results suggest it may serve as a powerful top-down modulator of olfactory cortical function and odor perception. Furthermore, the results provide potential insight into how neuropathology in the entorhinal cortex could contribute to early olfactory deficits seen in Alzheimer's disease.

\section{Introduction}

The entorhinal cortex is a component of the medial temporal lobe memory system, though is increasingly believed to have an important role in sensory perception (Baxter, 2009; Suzuki, 2009). In addition to connections with the hippocampus, the entorhinal cortex also receives dense input from the perirhinal cortex, amygdala, thalamus, and modulatory areas, such as the cholinergic medial septum (Canto et al., 2008). Entorhinal cortical neurons display intrinsic memory functions, for example maintaining stimulus-specific neural activity during delay periods (working memory; Egorov et al., 2002; Hasselmo and Stern, 2006). Finally, the entorhinal cortex appears uniquely sensitive to a number of disorders including Alzheimer's disease (Braak and

\footnotetext{
Received April 1, 2013; revised July 9, 2013; accepted July 15, 2013.

Author contributions: J.C., X.H., F.X., and D.A.W. designed research; J.C., Y.C., X.H., Z.Z., S.J., F.X., and D.A.W. performed research; J.C., Y.C., X.H., F.X., and D.A.W. analyzed data; J.C., Y.C., X.H., F.X., and D.A.W. wrote the paper.

This work was supported by NIH Grants DC003906 and AG037693 to D.A.W., and National Natural Science Foundation of China $(91132307 / \mathrm{H09}, 20921004)$ and Chinese Academy of Sciences (XDB02050500) to F.X. We thank Ed Callaway for providing various rabies viruses.

The authors declare no competing financial interests.

*J.C., Y.C., and X.H. contributed equally to this work.

Correspondence should be addressed to Donald A. Wilson, Emotional Brain Institute, Nathan Kline Institute for

Psychiatric Research, 140 Old Orangeburg Road, Orangeburg, NY 10962. E-mail: Donald.wilson@nyumc.org.

DOI:10.1523/JNEUROSCI.1387-13.2013

Copyright $\odot 2013$ the authors $\quad 0270-6474 / 13 / 3313449-11 \$ 15.00 / 0$
}

Braak, 1992; Braak et al., 2011), with layer II neurons particularly vulnerable (Stranahan and Mattson, 2010). For example, Alzheimer's disease related neuropathology appears to emerge first in the transentorhinal region (Braak and Braak, 1992; Braak et al., 2011).

In addition to its role in memory and cognition, the lateral entorhinal cortex (LEC) is also a component of the olfactory cortex, receiving input from both the main $\mathrm{OB}$ and piriform cortex (PCX). In fact, in rodents afferent fibers from olfactory areas are the dominant input to LEC (Kerr et al., 2007). This input terminates in layer I on the apical dendrites of layer II/III pyramidal and stellate cells (Luskin and Price, 1983; Burwell and Amaral, 1998). In addition to the input from the olfactory bulb and PCX, the LEC projects directly back to both areas (Haberly and Price, 1978; Cleland and Linster, 2003; Agster and Burwell, 2009). This feedback originates from the same class of layer II/III neurons whose axons form the perforant path projection to the hippocampal formation (Agster and Burwell, 2009), whereas entorhinal cortex output to other, nonolfactory areas is predominantly from layer $\mathrm{V}$ pyramidal neurons. The LEC is responsive to objects (perhaps odorous) in an open field (Deshmukh and Knierim, 2011), and to odors (Boeijinga and Lopes da Silva, 1989; Eeckman and Freeman, 1990; Kay and Freeman, 1998; Chabaud et al., 2000; Kjelvik et al., 2012; Xu and Wilson, 2012) with singleunits more narrowly tuned than piriform cortical neurons $\mathrm{Xu}$ 

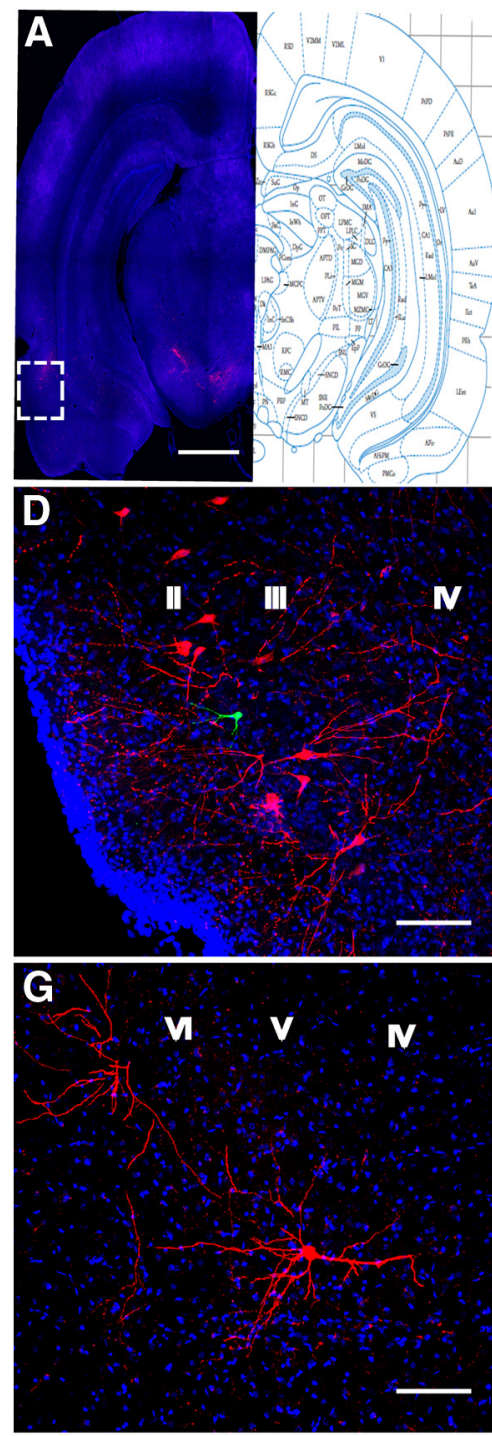
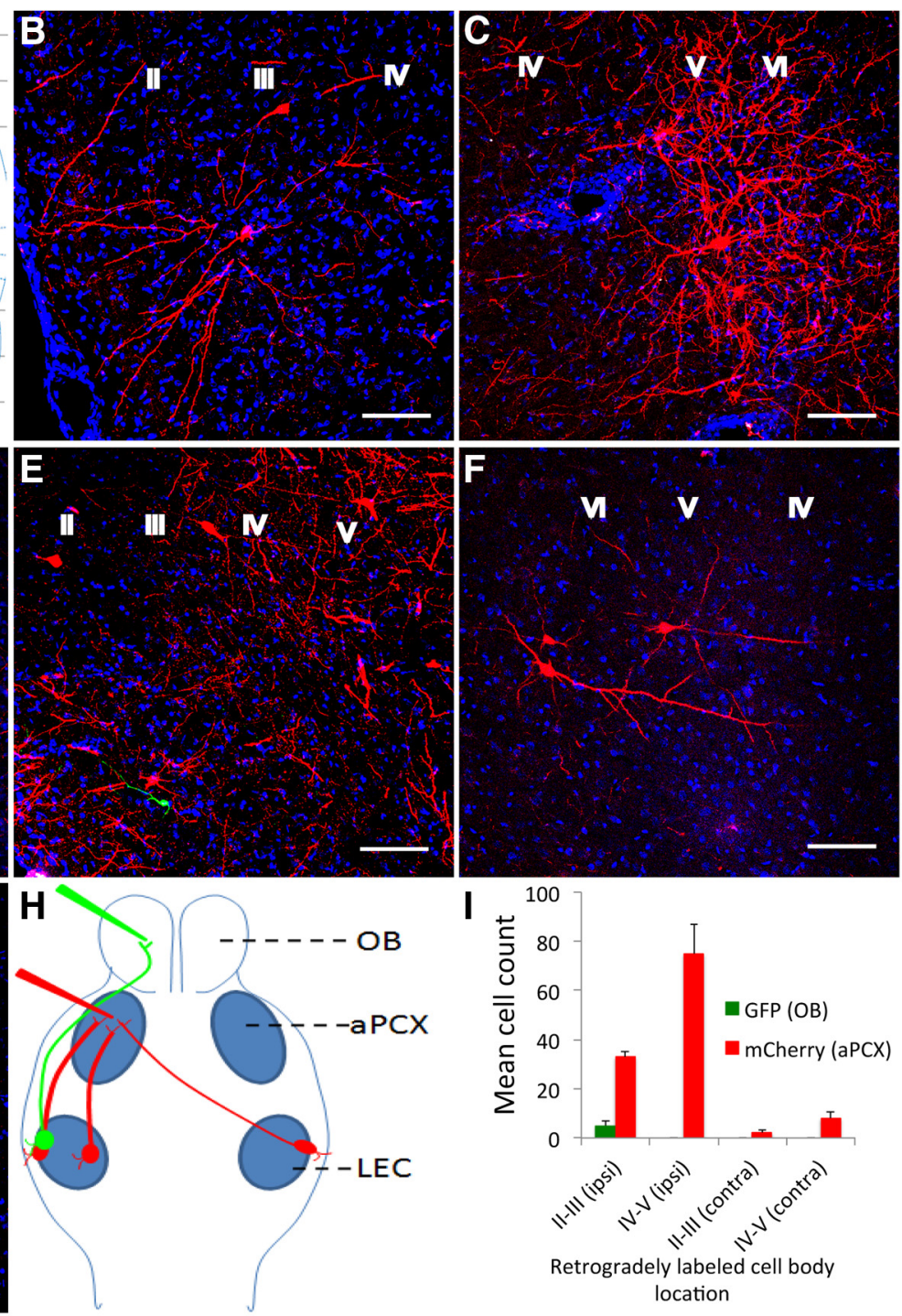

Figure 1. Retrogradely labeled neurons in LEC following viral injections into the olfactory bulb (GFP) or the aPCX (mCherry). Labeled neurons were distributed throughout the LEC, especially in layers II-V in the ipsilateral LEC, with the most robust labeling observed after aPCX infections. With these markers, no double-labeled cells were observed in any animal. $A$, Left, Section labeled with RV-GFP (olfactory bulb) and RV-mCherry (aPCX); right, annotated corresponding to the section (bregma 5.3) adapted from (Paxinos and Watson, 2009). Scale bar, $2 \mathrm{~mm}$. $\boldsymbol{B}$ - $\boldsymbol{E}$, Higher-magnification images of boxed regions in $(\boldsymbol{A}) . \boldsymbol{B}, \boldsymbol{D}$, High-magnification of lamina II-III. C, $\boldsymbol{E}$, High-magnification of lamina V-VI, from adjacent sections for illustration. Scale bar, $100 \mu \mathrm{m} . \boldsymbol{F}, \boldsymbol{G}$, High-magnification images of the labeled neurons in lamina V-VI in contra lateral LEC. Scale bar, $100 \mu \mathrm{m}$. $\boldsymbol{H}$, Schematic representation of the rabies viruses mediated retrograde tracing of the projection neurons from LEC to the olfactory bulb and aPCX. I, Quantification of mean cell counts across animals $(n=7)$ in the different lamina ipsilateral and contralateral to the $0 B$ and aPCX infections. Here and in all subsequent figures, data are presented as mean \pm SEM.

and Wilson, 2012). Furthermore, local field potential analyses reveal that in odor discrimination-trained animals the EC can signal the OB before odor onset, potentially preparing the system for odor sampling (Kay et al., 1996; Martin et al., 2007). Together, these features suggest the potential for the LEC to provide a highly odor-specific, memory, and expectation-dependent feedback to the olfactory bulb and olfactory cortex. Thus, loss or disruption of this feedback could interfere with odor memory and/or perception, potentially contributing to the known early impairment in olfactory perception associated with Alzheimer's disease (Mesholam et al., 1998; Murphy, 1999; Devanand et al., 2000; Segura et al., 2013).

Here, we explore the consequences of reversible LEC lesions on olfactory cortical activity and perception. The results suggest a robust modulation of both spontaneous and odor-evoked piriform cortical activity by the LEC, and a loss of fine odor discrimination ability during reversible LEC silencing.

\section{Materials and Methods}

Subjects were Long-Evans hooded (males, $>200 \mathrm{~g}$ ) or Spraque-Dawley (male, $200 \mathrm{~g}$, for anatomy) rats. All procedures were approved by the Institutional Animal Care and Use Committees at the Nathan Kline Institute and the New York University Langone School of Medicine, or by Animal Care and Use Committees at the Wuhan Institute of Physics and Mathematics, the Chinese Academy of Sciences. Tests were performed during the light portion of the light/dark cycle. Food and water were available ad libitum unless specifically noted.

Anatomy. Retrograde tracers derived from the rabies virus were used to reveal the direct projections from the LEC neurons to the olfactory bulb $(\mathrm{OB})$ and the anterior piriform cortex (aPCX). The rabies virus was kindly supplied by Edward Callaway and produced in our laboratory as previously described (Osakada et al., 2011). Seven Spraque-Dawley rats were used for virus tracing and all procedures on animals were performed in a BioSafety Level II animal facility. Animals were anesthetized with chloral hydrate $(500 \mathrm{mg} / \mathrm{Kg})$, and then placed in a stereotaxic apparatus (Stoelting). During surgery and virus injection, animals were kept anes- 

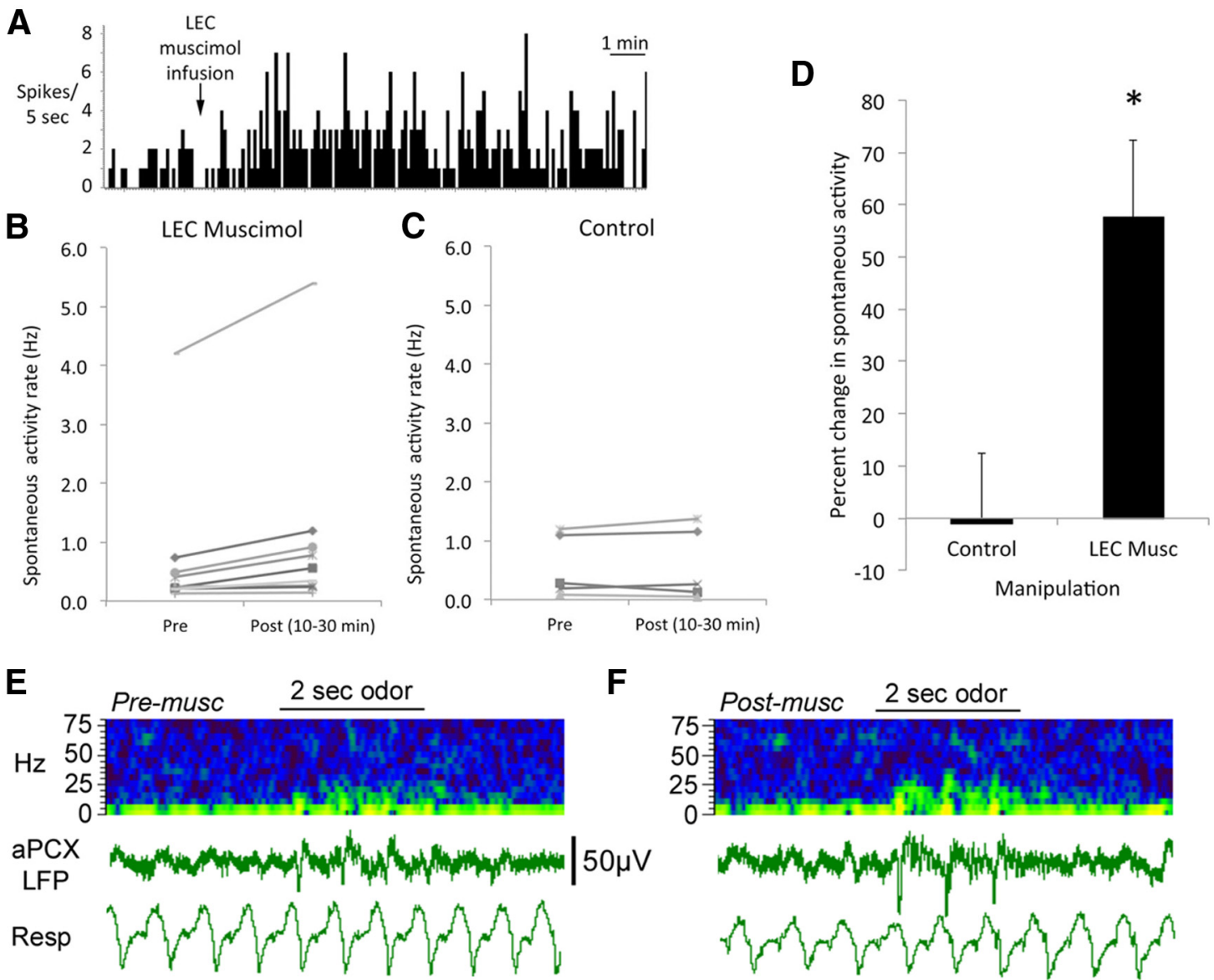

G
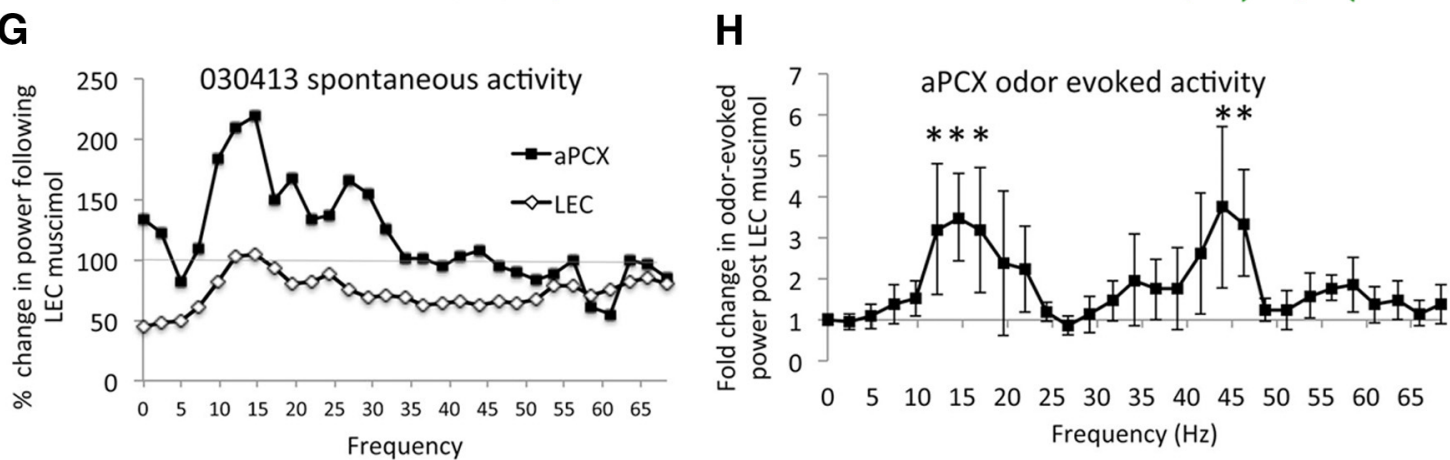

Figure 2. Spontaneous activity recorded in aPCX of urethane anesthetized rats was enhanced by muscimol infusion into the ipsilateral LEC. $A$, Representative example of increased aPCX single-unit firing rate within a few minutes of muscimol infusion into the ipsilateral LEC. $\boldsymbol{B}, 0$ f the 10 cells tested, nine showed enhanced activity after LEC infusion. $\boldsymbol{C}$, There was no spontaneous activity change after control (saline or no infusion) manipulations. $\boldsymbol{D}$, Silencing of the LEC with muscimol significantly enhanced ipsilateral aPCX single-unit $(n=10)$ spontaneous activity (asterisk represents significant difference from controls, $p<0.01)$. $\boldsymbol{E}$, Representative example of raw $L F P$ recording in aPCX and pseudocolor sonograph of the same data before $(\boldsymbol{E})$ and after $(\boldsymbol{F})$ muscimol infusion into the ipsilateral LEC. Pseudocolor show higher power in yellows and reds. Resp, Respiration from chestwall movement. Time scale ( $2 \mathrm{~s}$ ) and voltage scale are shown. $\mathbf{G}$, Representative quantitative example of change in LFP spontaneous activity in the aPCX and LEC (percentage change in power from pre-infusion) following muscimol infusion into the LEC. Note the relative depression of LEC activity and relative enhancement of aPCX activity. $\boldsymbol{H}$, Mean-fold change in aPCX odor-evoked LFP activity following ( $10-30$ min) LEC muscimol infusion $(n=4)$. Note particular enhancement in the beta and low gamma range in these anesthetized animals. Asterisks represent significant change from baseline. Asterisks represent significant change, $p<0.05$.

thetized with isoflurane (1\%). Two kinds of rabies viruses (titer $\sim 10 \%$ $\mathrm{Ml}$ ), RV- $\Delta \mathrm{G}$-GFP and RV- $\Delta \mathrm{G}$-mCherry, were injected ( $50 \mathrm{nl} / \mathrm{min}$ ) into the $\mathrm{OB}$ and the aPCX, respectively. To ensure enough projection fibers from the LEC were labeled, eight sites were chosen from the $O B$ and the aPCX, and each site was injected with $500 \mathrm{nl}$ rabies viruses. For the OB injection, the following anterior-posterior (AP) and medial-lateral (ML) coordinates relative to $\lambda$ were used (AP 7.7 and $8.5 \mathrm{~mm}$, ML 1.9 and 1.4 $\mathrm{mm}$ ), and the two dorsal-ventral (DV) coordinates to $\lambda$ were (DV -1.8 and $-3.2 \mathrm{~mm}$ ). For the aPCX injection, four sites were chosen and each site was injected with $1 \mu \mathrm{l}$ of rabies virus. The following coordinates were used for aPCX injection (AP $2.6 \mathrm{~mm}$, ML $3.8 \mathrm{~mm},-7.2 \mathrm{~mm}$; AP $2.1 \mathrm{~mm}$,
ML 3.8 mm DV -7.2 mm; AP 1.6 mm, ML 4.0 mm DV - 8.0 mm; AP 1.2 $\mathrm{mm}$, ML $4.5 \mathrm{~mm}$ DV $-7.9 \mathrm{~mm}$ ) Eight days after virus infection, the animals were transcardially perfused with physiological saline followed by $4 \%$ paraformaldehyde (PFA) solution. The brain was extracted, postfixed in PFA overnight, and dehydrated in 30\% (w/v) sucrose solution for $3 \mathrm{~d}$. The brain was sectioned coronally with a Leica VT1000S vibrating microtome. Sequential whole brain sections, with a thickness of $40 \mu \mathrm{m}$, were transferred into 24 well plates for storage. For florescent imaging, they were wet mounted on Vecta-shield (Vector Laboratories) mounting medium containing DAPI, sealed with nail polish, imaged with an inverted fluorescence confocal microscopy (Nikon). The acquired images 
were adjusted with NIS-element viewer 4.0, and processed with Adobe Photoshop CS4 and Adobe Illustrator CS 6.0 for illustration. Seven coronal sections from bregma -5.1 to -6.2 of the labeled brains were selected to count the mean number of labeled neurons.

Acute electrophysiology. Animals were anesthetized with urethane $(1.5 \mathrm{~g} / \mathrm{kg})$ and placed in a stereotaxic apparatus. A tungsten microelectrode was inserted into the aPCX under physiological control based on responses to lateral olfactory tract stimulation. A cannula was inserted into the ipsilateral LEC $(6 \mathrm{~mm}$ posterior, $6 \mathrm{~mm}$ lateral to bregma, and $6 \mathrm{~mm}$ ventral to the brain surface). In some animals, the cannula was attached to an electrode to record LEC activity before and after muscimol infusions. Both single-unit activity and local field potentials (LFPs) were recorded in the aPCX, including spontaneous activity and odorevoked activity (2 s odor pulses, stimuli included monomolecular odorants and mixtures). Signals were bandpass filtered and amplified (A-M Systems) and acquired and analyzed with Spike2 software (Cambridge Electronic Design). Signals were digitized at $10 \mathrm{kHz}$. A standard session involved recording stable spontaneous and odor-evoked single-unit and LFP activity for 15-30 min, followed by muscimol infusion $(0.5 \mu \mathrm{g}$ in 0.5 $\mu \mathrm{l})$ into the ipsilateral LEC. Data recording continued for up to $1 \mathrm{~h}$ postinfusion. Single-units were isolated by template matching and principal component analysis of spike waveforms using standard Spike2 algorithms. Single-units showed at least a $2 \mathrm{~ms}$ absolute refractory period in interval histograms. Only single-units maintained for the duration of the recording are included in the data. Controls included saline $(0.5 \mu \mathrm{l})$ and sham infusions in different animals. Analyses included spontaneous firing rate pre- and post-LEC (10-30 min) infusion, single-unit activity entrainment to LFP beta oscillations, and LFP oscillations analyzed with FFT ( $2.4 \mathrm{~Hz}$ resolution). Single-unit entrainment to LFP beta oscillations was performed by first extracting a time stamp for each beta oscillatory wave. The LFP was digitally bandpass filtered to $15-35 \mathrm{~Hz}$ and negative oscillatory peaks extracted by thresholding at two times the SD of the filtered signal. Phase plots of single-unit activity were then constructed relative to these time stamps and analyzed with Rayleigh statistics using MATLAB (MathWorks) subroutines for circular statistics called CircStat (Berens, 2009). Vector length and angle were also calculated for each cell using CircStat. All analyses were performed on each cell both before and after (10-30 min) ipsilateral LEC muscimol infusion. Following the termination of testing, animals were overdosed with anesthetic, transcardially perfused with $10 \%$ formalin, and brains sectioned to confirm electrode and cannula placements.

Chronic electrophysiology. Bilateral, bipolar stainless steel electrodes (127 $\mu$ diameter wire) were implanted into the aPCX layer III under isoflurane anesthesia. Electrodes and a ground lead were cemented to the skull with dental acrylic and attached to a connector. In some animals, guide cannula's (Plastics One) were implanted at the same time into the LEC ( $6 \mathrm{~mm}$ posterior, $6 \mathrm{~mm}$ lateral to bregma, and $6 \mathrm{~mm}$ ventral to the brain surface). Following at least 1 week of recovery, the head connector was attached to a telemetry transmitter (EMKA Technologies) which allowed free movement and performance in the odor discrimination task while recording LFP's. Signals are transmitted at $1 \mathrm{KHz}$ to the telemetry receiver and then fed to an analog to digital converter and acquired and analyzed with Spike2 software. LFP recordings were synchronized with simultaneously recorded behavioral markers (sampling and water port entries and exits) in the operant chamber (Vulintus).

To examine the effects of muscimol infusion into the LEC on aPCX activity, a within animal designed was used. Animals performing a well learned odor discrimination task received a unilateral infusion of musci$\mathrm{mol}(0.5 \mu \mathrm{g}$ in $0.5 \mu \mathrm{l})$ through a cannula inserted into the guide cannula. The infusion rate was $0.2 \mu \mathrm{l} / \mathrm{min}$ and the internal cannula left in place at
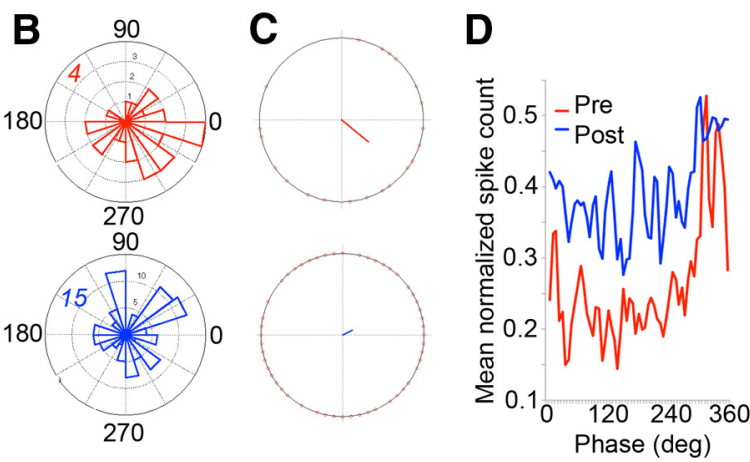

Figure 3. aPCX single-unit entrainment to aPCX LFP beta oscillations is reduced by LEC muscimol in anesthetized animals. $\boldsymbol{A}$ Representative example of aPCX single-unit entrainment to LFP beta oscillation recorded in aPCX before and during ipsilateral LEC muscimol infusion. Average beta cycle shown at top. $\boldsymbol{B}$, Polar plot of activity from the cell shown in $\boldsymbol{A}$ relative to beta oscillation

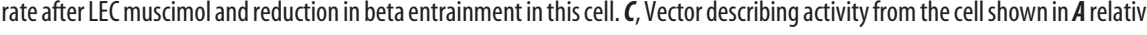
activity ( $n=9$ cells) relative to beta oscillation phase before and after ipsilateral LEC muscimol infusion. Note the increase in firing rate after LEC muscimol and reduction in beta entrainment.

least $5 \mathrm{~min}$ after the end of the infusion. The animal was then placed into the operant chamber for a $30 \mathrm{~min}$ session (see below). Controls procedures in the same animals included no infusion or saline infusion $(0.5$ $\mu \mathrm{l})$, with the conditions presented in a counterbalanced order across animals. Analysis of aPCX activity during the task was performed with FFT (3.9 Hz resolution). Analyses focused on the $1 \mathrm{~s}$ period immediately before entering the odor sampling port and the $1 \mathrm{~s}$ period immediately after entering the odor sampling port. Although as described in Results, a variety of cognitive processes are occurring during these time periods, for simplicity they are referred to here as "spontaneous" and "odorsampling" related activity. Within animal comparisons of aPCX activity were made both across hemispheres and across days (muscimol vs control). Following the termination of testing, animals were overdosed with anesthetic, transcardially perfused with $10 \%$ formalin, and brains sectioned to confirm electrode and cannula placements.

Behavioral training and testing. Animals were given limited access to water during behavioral training. Odor discrimination was assessed in a two-alternative forced choice, Go-Left, Go-Right odor discrimination task for water reward. Animals received $30 \mathrm{~min}$ training sessions, 5 $\mathrm{d} /$ week. The operant chamber was a Plexiglas box $(30 \times 30 \times 40 \mathrm{~cm})$ with a central odor port and two water ports on the left and right walls (Vulintus). Trials were initiated by a nose poke in the odor port (at least $350 \mathrm{~ms}$, with odor onset beginning $100 \mathrm{~ms}$ after poke onset). Odor delivery terminated on nose withdrawal from the port. Water reward was delivered, depending on odor identity, upon a correct choice of the left or right reward port. All the animals were first trained on a vanilla versus peppermint discrimination until criterion (performance $>80 \%$ ) was attained. Animals reached this criterion in (mean \pm SD) $14 \pm 3 \mathrm{~d}$.

Following criterion performance in the vanilla-peppermint discrimination, animals were anesthetized with isoflurane and bilateral guide cannulas were implanted in the LEC and cemented to the skull with dental acrylic. The animals were allowed at least 1 week to recover, and then began training in one of two mixture discrimination tasks. For mixture discrimination training, animals were presented with complex, 10 component, odorant mixtures (Barnes et al. (2008) describes the mixture preparation). The full 10 component mixture (10c) included the following monomolecular odorants: isoamyl acetate, nonane, ethyl valerate, 5-methyl-2-hexanone, isopropylbenzene, 1-pentanol, 1,7octadiene, 2-heptanone, heptanal, 4-methyl-3-penten-2-one. Odorants were diluted in mineral oil to obtain a concentration for each component of $100 \mathrm{ppm}$, based on vapor pressure. The $10 \mathrm{c}$ mixture was manipulated to produce two similar stimuli; the first one was the $10 \mathrm{c}$ original mix with one component (isoamyl acetate) missing (10c-1). The second one was the $10 \mathrm{c}$ original mix with one component (isoamyl acetate) replaced by 
A

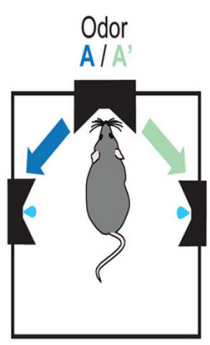

C Tubing only
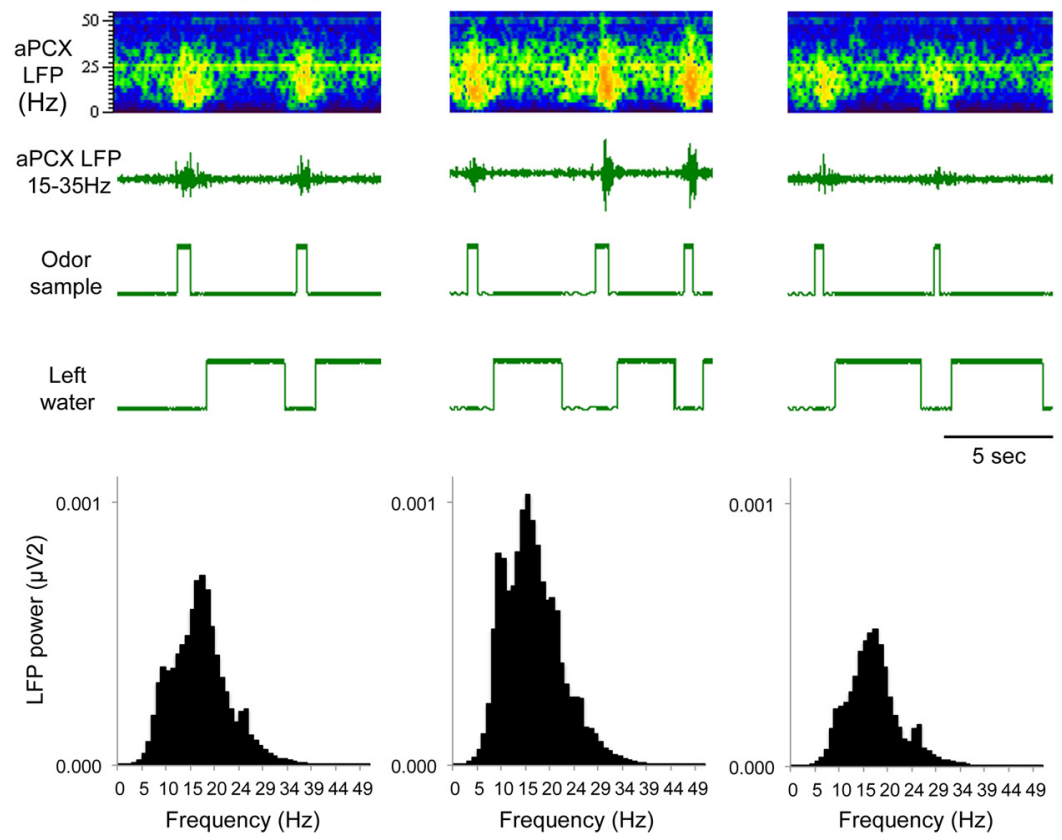

Figure 4. A, Animals were trained in a go-left, go-right, two-alternative forced-choice odor discrimination task. B, Comparison of discrimination task difficulty as determined by initial rate of acquisition from 4 representative animals in each task. The $10 \mathrm{C}$ versus 10-1 discrimination required significantly more trials to reach criterion than the 10c versus $10 \mathrm{cR} 1$ task as previously reported (Barnes et al., 2008; Chapuis and Wilson, 2012). C, An example of LFP beta-band activity (signals digitally filtered 15-35 Hz) recorded in $\mathrm{APCX}$ of a rat performing in the two-alternative forced-choice task under control conditions and during unilateral infusion of muscimol $(0.5 \mathrm{mg})$ or saline into the LEC. The treatments occurred over the course of three consecutive days in the order shown. "Odor sample" marks the time spent in the odor sampling port on a given trial, whereas "left water" marks the time spent in the left water delivery port. For simplicity no choices to the right are shown. LEC silencing enhanced aPCX oscillations (beta activity during odor sampling shown) in behaving rats, which recovered to normal the following day under saline infusion. Top, Time $\times$ frequency pseudocolor plots of power aligned to the LFP recordings and behavioral markers immediately below. Total power within the beta frequency band during odor sampling are plotted for the three conditions at bottom.

another contaminant (2-methyl-2-buten-1-ol) (10cR1). Extensive previous work has demonstrated that learning to discriminate $10 \mathrm{c}$ from $10 \mathrm{c}-1$ is significantly more difficult than learning to discriminate $10 \mathrm{c}$ from 10cR1 with these odorant configurations (Barnes et al., 2008; Chapuis and Wilson, 2012; Chen et al., 2011; Lovitz et al., 2012). Furthermore, the difficult training induces changes in single-unit, ensemble, and LFP responses in the aPCX that do not emerge after the simpler 10c versus 10cR1 training (Chapuis and Wilson, 2012).

After reaching criterion on either the easy (10c vs 10cR1) or difficult (10c vs 10c-1) tasks, animals were tested under three different conditions in a counterbalance order, with at least $3 \mathrm{~d}$ between manipulations. Animals received either bilateral muscimol infusions $(0.5 \mu \mathrm{g}$ in $0.5 \mu \mathrm{l})$, saline infusions $(0.5 \mu \mathrm{l})$, or sham infusions into the LEC immediately before being placed in the operant chamber. Within animal comparisons of percentage correct performance were made between infusion condition, and between animal comparisons made between odor tasks. Finally, the total time spent in the odor sampling port was compared across infusion conditions and discrimination tasks.

Following the termination of testing, animals were overdosed with anesthetic, transcardially perfused with $10 \%$ formalin, and brains sectioned to confirm cannula placements.

\section{Results}

LEC projections to the OB and aPCX

To reveal the distribution patterns of the LEC neurons that innervate the $\mathrm{OB}$ and the aPCX, we injected rabies virus RV$\Delta \mathrm{G}$-GFP into the $\mathrm{OB}$ and $\mathrm{RV}-\Delta \mathrm{G}$ mCherry into the aPCX. As shown in Fig. 1 , the rabies viruses injected into both the $\mathrm{OB}$ and the aPCX retrogradely labeled neurons in the LEC. The results clearly demonstrated the LEC projection to both regions within individual animals. Among the viral-labeled neurons in LEC, mCherry+ neuron somata were distributed in lamina II-V of the ipsilateral LEC (Fig. 1A-E), with highest mean cell counts in lamina V-VI. Labeled neurons were also observed in the contralateral LEC following aPCX infection, though in much reduced numbers (Fig. $1 F, G$ ). GFP+ neurons following infection of the $\mathrm{OB}$ were only distributed in the lamina II of ipsilateral LEC(Fig. 1D,E). Qualitative analyses revealed that injections into the aPCX labeled more LEC cells compared with the OB injections. These data showed that the LEC neurons innervating different regions (the ipsilateral $\mathrm{OB}$, ipsilateral aPCX, and contralateral aPCX) have different spatial distributions (lamina) in the LEC, and with different relative proportions (Fig. $1 H, I$ ). Furthermore, in those cases where cells projecting to the $\mathrm{OB}$ and aPCX were located in the same LEC lamina, no double-labeled cells were ever observed in any of the seven animals examined (Fig. 1D,E). This lack of doublelabeling either reflects segregated populations of LEC neurons projecting to the $\mathrm{OB}$ and aPCX, or may reflect the relatively small numbers of OBprojecting cells labeled here.

LEC suppression enhances aPCX activity in anesthetized rats Spontaneous single-unit activity was recorded in aPCX of urethane anesthetized rats ( $n=8$ rats). Following recording of stable activity for at least $10 \mathrm{~min}$, the LEC was infused with $0.5 \mu \mathrm{l}(0.5$ $\mu \mathrm{g}$ ) of muscimol or $0.5 \mu \mathrm{l}$ of saline ipsilateral to the aPCX record- 
ing to reduce or silence LEC activity. As shown in Figure 2, spontaneous singleunit activity was significantly enhanced following the LEC silencing by muscimol infusion ( $n=9$ units) compared with controls ( $n=7$ units; paired $t$ test, $t_{(14)}=$ $2.84, p<0.02)$. Thus, even under anesthetized conditions where top-down signals may be expected to be minimal, the LEC strongly suppressed aPCX single-unit spontaneous activity.

LFP oscillations in the aPCX were also enhanced following LEC muscimol infusion in anesthetized animals $(n=4)$. Figure $2 E$ shows representative effects in the aPCX and LEC following LEC muscimol in an individual rat. LEC spontaneous LFP oscillations were reduced up to $50 \%$ following (10-30 min) LEC muscimol while simultaneously LFP oscillations in the aPCX were enhanced. As shown in Figure $2 F$, odor-evoked oscillations in the aPCX were enhanced following ipsilateral LEC muscimol (frequency $\times$ time, repeated-measures ANOVA, min effect of time, $\left.F_{(1,87)}=8.38, p<0.01\right)$. The enhancement was most pronounced in the beta and low-gamma frequency bands (individual frequency post hoc tests, $p<0.05$ ).

Although both LFP beta band oscillations and single-unit activity were enhanced following ipsilateral LEC silencing, the entrainment of single-unit firing to beta oscillations was significantly reduced (Fig. 3). Mean vector length (possible range $0-1$ ) of single-unit entrainment to beta oscillations was reduced from $0.31 \pm 0.08$ pre-LEC infusion to $0.14 \pm 0.04$ post-LEC muscimol infusion (paired $t$ test, $t_{(8)}=2.34, p<0.05$ ).

\section{LEC suppression enhances piriform} cortical oscillations in awake rats

Animals $(n=6)$ were trained on a simple odor discrimination task in a twoalternative forced-choice task, with vanilla and peppermint as the discriminatory stimuli (Fig. 4A). Following successful training to criterion ( $85 \%$ correct), the animals were implanted with bilateral, bipolar electrodes in the aPCX and a guide cannula in the LEC. Following at least 1 week of recovery, the animals were trained in a mixture discrimination task (10c vs 10cR1). As the animals reached criterion, aPCX LFP's were recorded bilaterally with an EMKA telemetry system. After 1 or more baseline recording sessions (30 min training session/d), they received a unilateral infusion of muscimol $(0.5 \mu \mathrm{g} / 0.5 \mu \mathrm{l})$ or saline $(0.5 \mu \mathrm{l})$ into one LEC and placed in the training chamber. Unilateral LEC silencing had no effect on
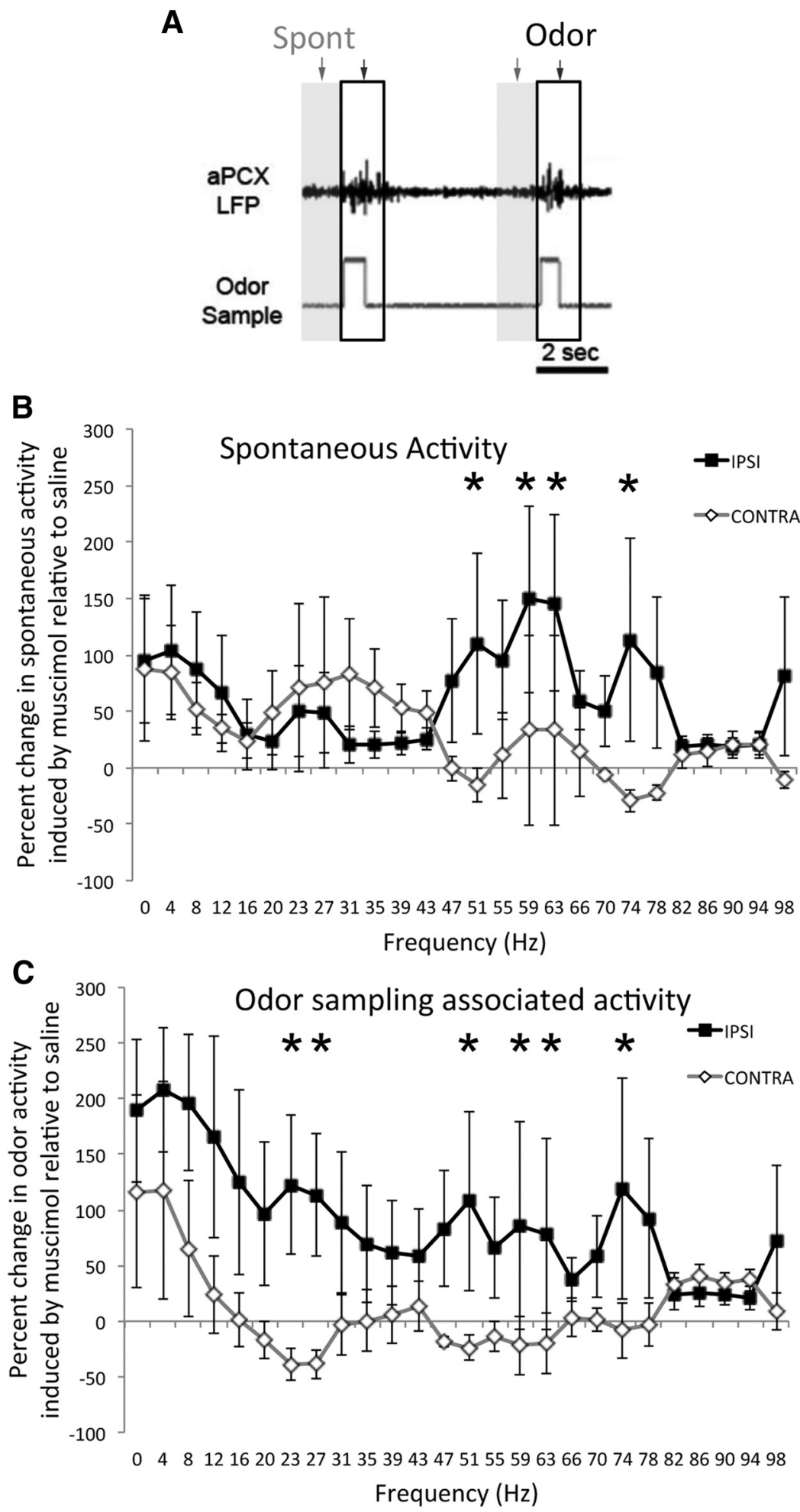

Figure 5. Unilateral muscimol infusions into the LEC enhanced LFP oscillations during odor sampling in the ipsilateral aPCX of rats performing in an odor discrimination task. $A$, FFT analyses were performed during the 1 s immediate pre-odor sampling period ("spontaneous", gray shaded region) or during $1 \mathrm{~s}$ beginning at the start of odor sampling (outlined region), across all trials in a session. $\boldsymbol{B}$, Change in LFP power during LEC muscimol infusions relative to control (saline) infusions for both the aPCX ipsilateral to the infusion and contralateral. LEC silencing induced a significant enhancement in spontaneous gamma frequency oscillations in the ipsilateral aPCX compared with the contralateral aPCX (within animal comparisons, $n=6$ ). C, During odor sampling both beta and gamma frequency oscillations were enhanced ipsilateral to the silenced LEC. Asterisks signify significant $(p<0.05)$ post hoc comparisons between ipsilateral and contralateral change. 
A

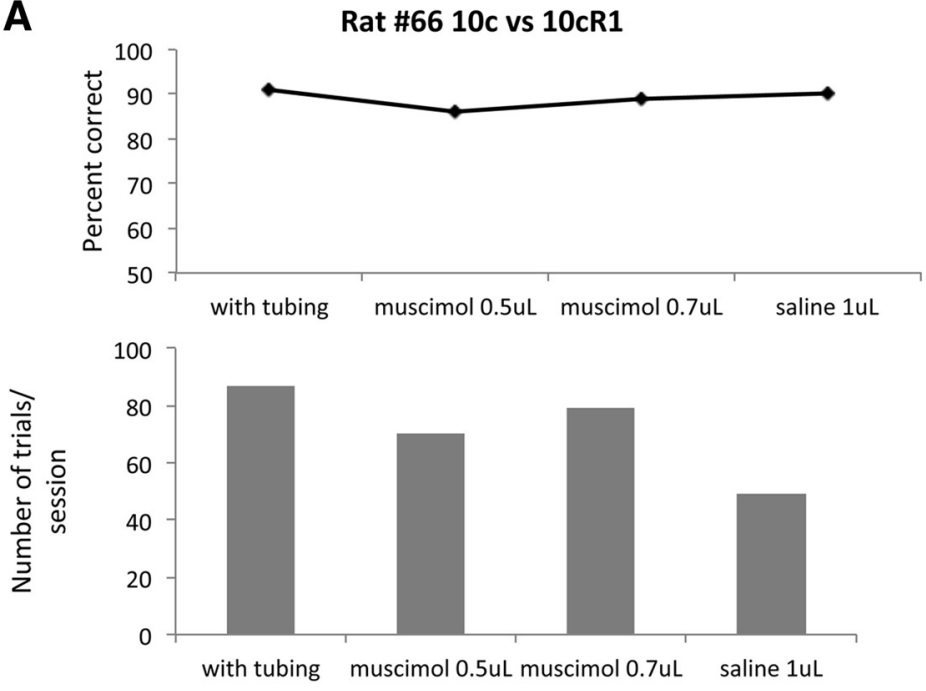

B
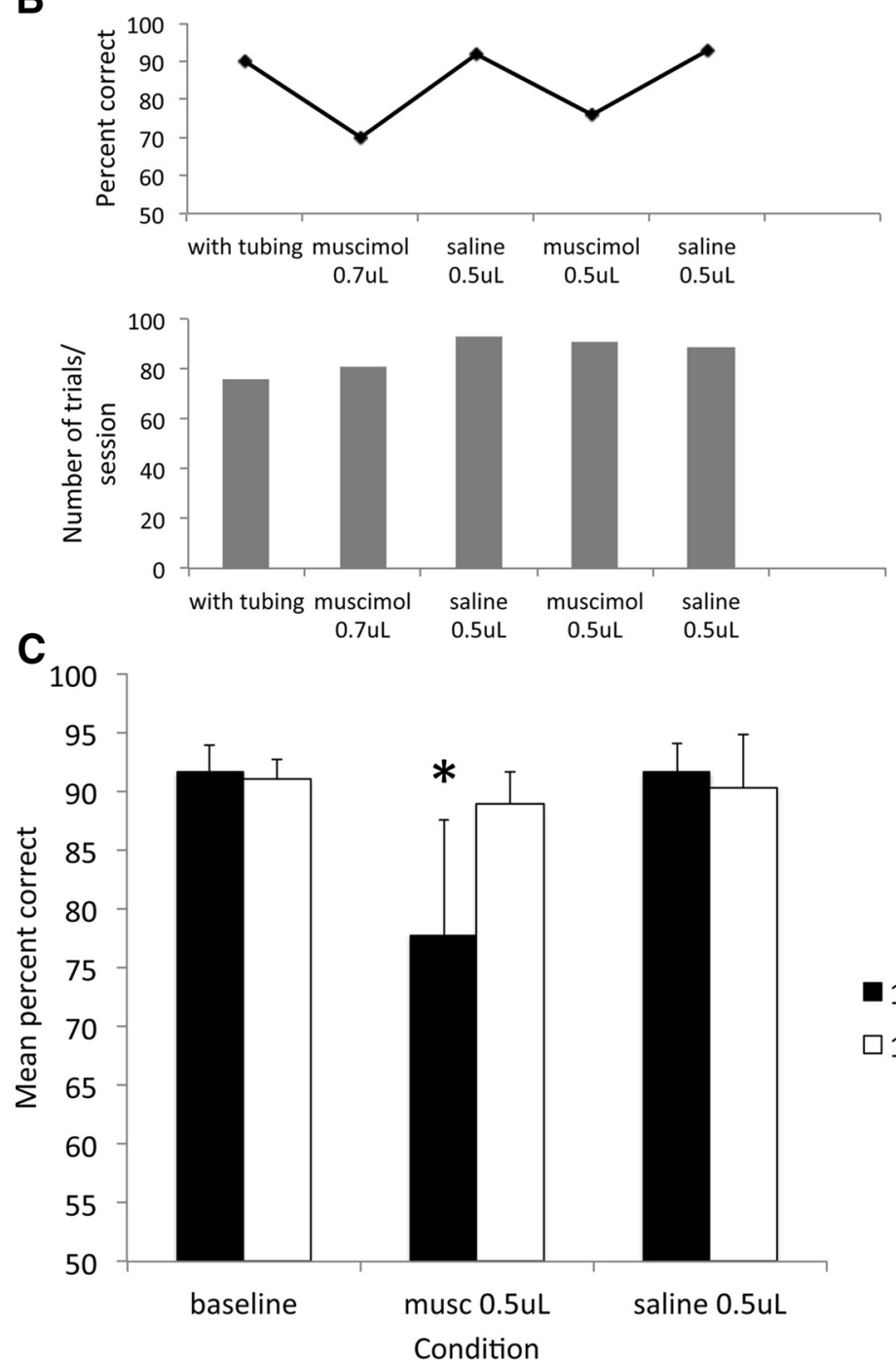

Figure 6. Bilateral muscimol infusion into the LEC of rats performing an two-alternative forced-choice task impaired fine odor discrimination but did not impact gross odor discrimination. $A$, Bilateral infusion of $0.5 \mathrm{mg}$ of muscimol into the LEC had no effect on a simple odor discrimination (10 c vs 10R1). Each manipulation in this animal was performed on different days in the order shown. Infusion of larger volumes ( $1 \mathrm{mg}$ ) did impair discrimination but also impaired response rats and general behavior. $\boldsymbol{B}$, Bilateral infusion of $0.5 \mathrm{mg}$ of muscimol in the LEC impaired discrimination of two highly similar odorant mixtures, without any reduction in general performance (trials initiated). C, Bilateral LEC silencing impaired performance on a well learned but difficult trial generation or performance (data not shown). However, there was a significant enhancement in aPCX LFP oscillations ipsilateral to the LEC silencing (Fig. 4C). LFP activity was analyzed with FFTs during $1 \mathrm{~s}$ bins either immediately before entry in to the odor sampling port or beginning when the animal entered the odor sampling port (Fig. 4A). For clarity, the period before odor sampling is referred to here as spontaneous activity, though this period could include termination of water reward consumption, movement toward the odor sampling port and/or anticipation of odor sampling. The $1 \mathrm{~s}$ period beginning at entry to the odor sampling port is referred to here as odor sampling related activity, though it may also include exit from the sampling port and movement toward the water reward port, with the associated anticipation of water reward. The activity during these periods was expressed as percentage change during muscimol infusion compared with control (saline or no infusion), and determined for both the aPCX ipsilateral to the LEC infusion and the hemisphere contralateral to the infusion (allowing a within animal comparison). This comparison between manipulated and control hemispheres allowed us to eliminate the possible contribution of respiratory or other bilateral movement changes that could contribute to observed LEC infusion-induced changes in cortical LFP activity.

As shown in Figure 5, LEC silencing enhanced oscillation power in the gamma frequency spectrum during "spontaneous" activity in the aPCX ipsilateral to the infused LEC compared with the contralateral aPCX. Minimal change was observed in the other frequency bands (repeatedmeasures ANOVA, side $\times$ frequency, Main effect of side, $F_{(1,78)}=13.14, p<0.001$; post hoc Fisher tests used to confirm significance of individual frequency comparisons). In contrast, during odor-sampling associated activity, power in both the beta and gamma frequency spectra were enhanced in the aPCX ipsilateral to the LEC infusion compared with the contralateral hemisphere (repeated-measures ANOVA, side $\times$ frequency, main effect of side; $F_{(1,78)}=19.96$, $p<0.001$; post hoc Fisher tests used to confirm significance of individual frequency

\section{$\leftarrow$}

discrimination task ( $n=8)$, but had no effect on a well learned simpler task $(n=4)$. Asterisk signifies significant reduction $(p<0.05)$ in percentage correct in the muscimol condition for the $10 \mathrm{c}$ versus $10 \mathrm{c}-1$ discrimination compared with control conditions. 
comparisons). Thus, as in the anesthetized animals, loss of LEC topdown input in awake, performing animals induced abnormal enhancement of aPCX activity.

\section{LEC suppression impairs fine odor discrimination}

Separate animals $(n=12)$ from those used above were implanted with bilateral LEC guide cannulas following successful training in the simple vanilla versus peppermint discrimination. Following recovery, the animals were trained in a well described (Barnes et al., 2008; Chapuis and Wilson, 2012; Chen et al., 2011; Lovitz et al., 2012) mixture discrimination task, with four of the animals trained in a relatively easy mixture discrimination task (10c vs $10 \mathrm{cR} 1$ ) and eight trained in the more difficult (10c vs 10-1) mixture discrimination task (see Materials and Methods for description of odor mixtures). After the animals reached criterion on mixture discrimination, they received bilateral infusions of muscimol into the LEC immediately before their next training session, or received control manipulations (two controls: saline infusion and tubing attached with no infusion; one animal in the easy training task did not receive saline). The order of manipulations was counter balanced across animals and at least $3 \mathrm{~d}$ elapsed between manipulations, with normal training during the intervening days to confirm no lasting effects of the manipulations. There was no effect of infusate on the total number of trials generated during the $30 \mathrm{~min}$ session (sham, mean $=96.2 \pm 5.2 ; 0.5 \mu \mathrm{g}$ muscimol, mean $=102.5 \pm 7.7$; saline, mean $=93.2 \pm 7.8$ ).

As shown in Figure $6,0.5 \mu \mathrm{g}$ of muscimol infused bilaterally into the LEC had no effect on discrimination performance with the easy discrimination, but significantly impaired performance on the difficult discrimination task. A $2 \times 3$ (task $\times$ infusion condition) repeated-measures ANOVA revealed a significant task $\times$ infusion condition interaction $\left(F_{(2,18)}=3.79, p<0.05\right)$. Further analyses revealed that the LEC muscimol infusion significantly impaired performance on the well learned difficult discrimination task (10c vs $10 \mathrm{cR} 1, F_{(2,14)}=14.55, p<0.001$, post hoc tests confirmed lower percentage correct during LEC muscimol compared with other conditions, $p<0.05)$. Similar analyses revealed no significant effect of LEC muscimol on performance on the easy $10 \mathrm{c}$ versus $10 \mathrm{cR} 1$ task $\left(F_{(2,4)}=0.67\right.$, n.s. $)$. There was no significant effect on the number of trials generated during the session for any infusate.

The fact that performance on the easy task was unaffected by LEC muscimol suggests that the entorhinal cortex is not required for performance or for basic memory components of the task, as previously demonstrated with permanent entorhinal cortex lesions before initial training (Eichenbaum et al., 1988; Otto and Garruto, 1997). However, to confirm that olfactory cues were required for performance of the easy task, another group of animals $(n=5)$ were implanted with bilateral cannulas aimed at the aPCX. Following training to criterion on the $10 \mathrm{c}$ versus $10 \mathrm{cR} 1$ task, the animals received bilateral muscimol infusions into the aPCX with the same parameters as used for the LEC infusions $(0.5 \mu \mathrm{l})$ or saline (counterbalanced order). This is a small infused volume compared with volumes typically used for PCX (Best et al., 2005; Smith et al., 2009). Nonetheless, as shown in Figure 7, performance in the easy odor discrimination task was significantly impaired by bilateral muscimol infusions into the aPCX (repeated-measures ANOVA, $F_{(2,8)}=14.74, p<0.01$; post hoc test revealed a significant reduction in percentage correct during the muscimol infusion compared with both other conditions, $p<0.05)$.

Finally, previous work has suggested that animals can modify their odor sampling time depending on the difficulty of the dis-
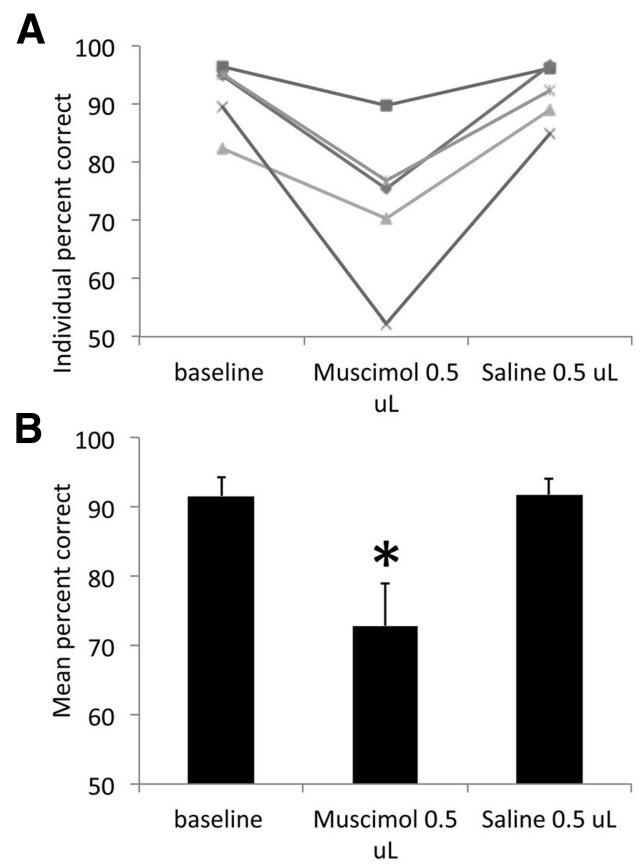

Figure 7. Bilateral infusion of muscimol into the aPCX impaired gross odor discrimination (10c vs 10cR1). A, Although LEC muscimol infusions had no effect on this discrimination task (Fig. 5), mucimol infusion into the aPCX was sufficient to impair discrimination in all animals $(n=5)$ compared with control conditions. $\boldsymbol{B}$, Performance during muscimol infusion was significantly impaired compared with control conditions. Asterisk represents significant difference from controls, $p<0.05$.

crimination task (Abraham et al., 2004; Rinberg et al., 2006; Uchida et al., 2006; Smith et al., 2009; Lovitz et al., 2012). Here we examined whether animals modified the time spent in the odor sampling port during LEC muscimol infusions compared with saline. As shown in Figure 8, although there was a trend for increased time in the odor sampling port during the difficult $10 \mathrm{c}$ versus 10c-1 task compared with the easier task, and a trend for increased time in the port during muscimol infusions on both tasks, these effects were not significant (task $\times$ infusion repeatedmeasures ANOVA, main effect of infusion, $F_{(1,9)}=3.31, p=$ 0.10 ; main effect of task, $F_{(1,9)}=0.31$, n.s.).

\section{Discussion}

The present results demonstrate a strong, top-down modulation by the entorhinal cortex on aPCX single-unit and network activity, as well as behavioral fine odor discrimination. The physiological changes following LEC suppression are consistent with an LEC-mediated inhibition of PCX, which would require involvement of local inhibitory interneurons. Furthermore, given that the LEC projects to both the PCX and the OB (Fig. 1; Insausti et al., 1997; Agster and Burwell, 2009), some of the effects observed in aPCX may be indirect, due to LEC modulation of OB output. Indirect modulation of the aPCX via LEC projections to other, nonolfactory areas (Insausti et al., 1997) may also contribute to our results. The specific cellular targets of LEC input to the $\mathrm{OB}$ and PCX are not presently known, though given the targets of other afferents to the PCX (such as the basolateral amygdala; Luna and Morozov, 2012) both pyramidal cells and inhibitory interneurons may receive synaptic input.

The results are consistent with earlier reports using electrolytic or aspiration lesions of the entorhinal/perirhinal cortex suggesting a top-down entorhinal cortex suppression of piriform cortical activity (Bernabeu et al., 2006; Mouly and Di Scala, 2006) 
A

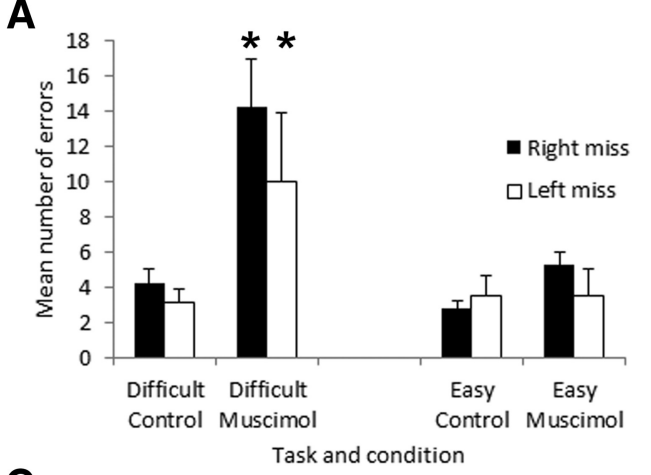

C

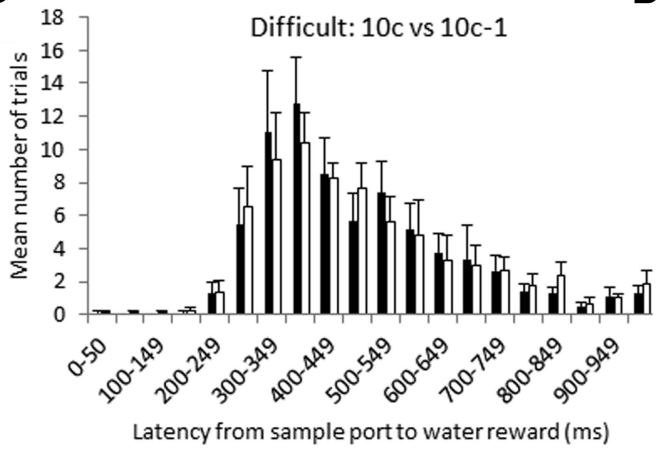

B
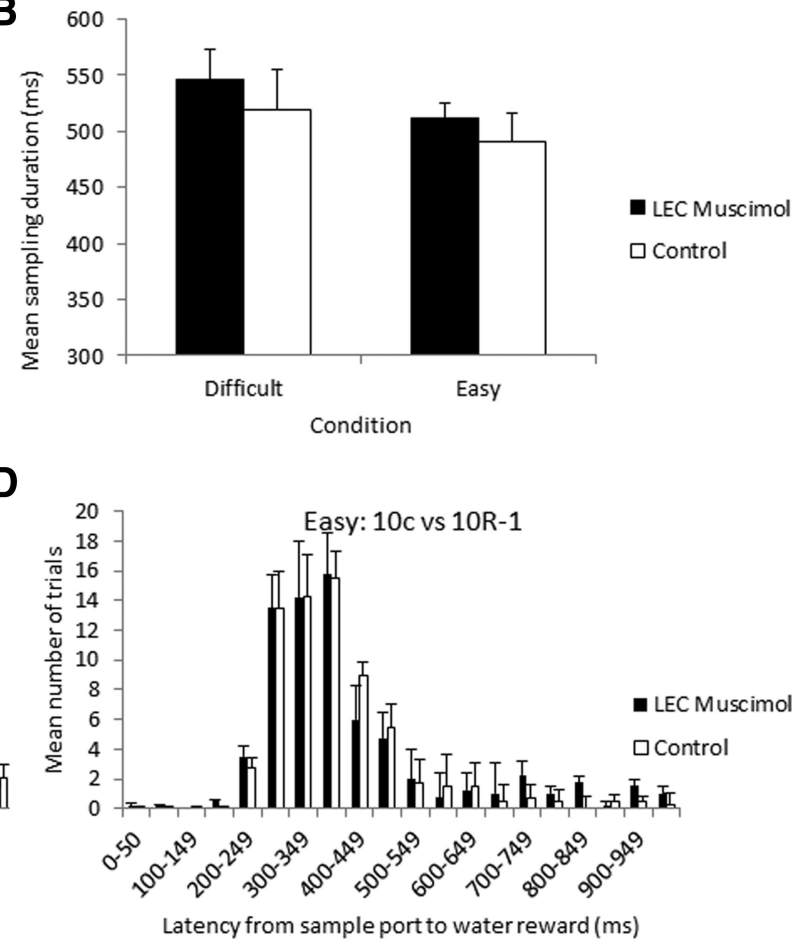

Figure 8. Impairment the discrimination task in LEC infused rats was not due to general behavioral performance deficits. $\boldsymbol{A}$, Bilateral LEC muscimol infusions significantly increased error rate in the difficult task comparably between left and right choices. Asterisks signify significant difference between difficult muscimol condition from all other conditions ( $p<0.05$ ). $\boldsymbol{B}, 0 \mathrm{dor}$ sampling time (duration in the odor sampling port) was not significantly modified by bilateral LEC muscimol infusion. There was a trend toward extended sampling times in the difficult task ( $10 \mathrm{c}$ vs $10 \mathrm{c}-1 ; n=8$ rats) compared with the easy task (10c vs $10 R 1, n=4$ rats), though this difference was not significant and was not significantly affected by LEC muscimol. $\boldsymbol{C}, \boldsymbol{D}$, Latency to move from the odor sampling port to the water reward ports was not changed in either task by LEC muscimol. Mean distribution of response latencies are shown for both tasks and infusion conditions.

and modulation of olfactory learning and memory (Otto et al., 1991; Ferry et al., 1996; Otto and Garruto, 1997; Wirth et al., 1998). However, the present results significantly extend these earlier findings by demonstrating that reversible suppression of LEC activity reversibly impairs discrimination of a well learned, but difficult discrimination requiring high olfactory acuity. Discrimination of a well learned but relatively easy discrimination was not impaired. These results argue for an important role of the LEC not only in odor learning (Otto et al., 1991; Ferry et al., 1996), but also in odor perception and discrimination of familiar odors. Recent work in normal aging humans also shows a strong correlation between entorhinal cortical volume and performance on the University of Pennsylvania Smell Identification Test (UPSIT), with smaller cortical volumes associated with poorer odor identification (Segura et al., 2013).

Feedback from the LEC to OB and PCX could convey a range of important information. First, this feedback is most likely highly odor specific, given that LEC single-units are more narrowly tuned than aPCX neurons (Xu and Wilson, 2012). Second, given the range of regions targeting the entorhinal cortex, including the amygdala, perirhinal cortices, and the hippocampus, LEC feedback most likely provides information regarding hedonic state, recent experience, and multisensory events. Activity in the LEC is also modulated by internal state, such as hunger and satiety (Chabaud et al., 2000). Given this rich contextual and historical information, LEC feedback could also contribute to anticipatory activity in the olfactory system (Kay et al., 1996; Engel et al., 2001), preparing $\mathrm{OB}$ and cortical circuits for expected odors (Schoenbaum and Eichenbaum, 1995).

In fact, both aPCX spontaneous (pre-odor sampling) and odor sampling-related activity were modified by LEC suppres- sion. Both types of activity were characterized by elevated gamma frequency $(35-90 \mathrm{~Hz})$ activity during LEC suppression compared with control. Gamma frequency activity in most regions of the brain including the olfactory system (Neville and Haberly, 2003; Kay et al., 2009) is typically believed to reflect local circuit activity (Buzsaki, 2006). Gamma frequency oscillations have been linked to such functions as attention, integration of sensory and multisensory signals, and memory formation (Engel et al., 2001; Jensen et al., 2007; Zion Golumbic et al., 2013). In the PCX and OB gamma oscillations occur in phase with the respiratory cycle and help synchronize spike trains (Buonviso et al., 2003; Litaudon et al., 2008; Cenier et al., 2009). In the OB, gamma oscillations appear to derive from granule cell-mitral cell (inhibitory-excitatory) synaptic interactions, and local circuit mechanisms may be similar in the PCX (Ketchum and Haberly, 1993a; Poo and Isaacson, 2009). The LEC may provide an important tonic and/or dynamic modulation of this excitatory-inhibitory balance to shape odor coding.

During odor stimulation, in addition to the gamma oscillation changes, LEC silencing also enhanced beta frequency oscillations in the aPCX. In sensory and motor neocortical systems, changes in beta oscillation power have been hypothesized to reflect the expectation of maintained status quo (Engel et al., 2001; Engel and Fries, 2010). Either abnormal increases or decreases in beta oscillation power appear to disrupt flexibility of behavior and performance (Engel and Fries, 2010). Beta frequency LFP oscillations in the aPCX may reflect reverberatory activity between the aPCX and OB (Neville and Haberly, 2003; Kay and Beshel, 2010) and/or between the OB and entorhinal cortex/hippocampal formation (Kay and Freeman, 1998). Given that activity in the LEC was reduced by muscimol infusions, whereas aPCX LFP beta os- 
cillations were enhanced, we hypothesize that the loss of LEC top-down suppression enhances OB-PCX excitability and thus enhances OB-PCX LFP beta oscillatory activity. This potential enhanced aPCX responsiveness to OB input could also contribute to the previously observed enhancement in odor-evoked c-fos activation in the PCX following entorhinal cortex lesions (Bernabeu et al., 2006), and enhancement of simple odor learning (Ferry et al., 1996; Wirth et al., 1998). Interestingly, the enhancement in the aPCX single-unit firing rate following LEC silencing was associated with a disruption in firing entrainment to locally recorded LFP beta oscillations (Fig. 3). Thus, there appeared to be dissociation between LEC silencing-induced enhancement in aPCX LFP beta oscillations and aPCX single-unit entrainment to beta oscillations. This loss of beta oscillation entrainment could impair odor information encoding by disrupting timing of afferent and association fiber driven cortical activity (Ketchum and Haberly, 1993a,b), and thus contribute to the disruption of fine behavioral sensory acuity. Given the relatively small cell counts and the relatively slow firing rates in these cells, however, additional work will be required to confirm this disassociation and its meaning.

It should be noted that these changes in piriform cortical LFP activity after LEC silencing were observed in both awake and anesthetized animals, and thus may reflect loss of tonic input rather than, or in addition to, task-specific modulation. Furthermore, the LFP recordings in awake animals here were only performed in animals trained in the relatively simple odor discrimination task (10c vs 10cR1). Beta and gamma band oscillations in the aPCX in intact rats have been shown to vary with the difficulty of odor discrimination (Kay and Beshel, 2010; Chapuis and Wilson, 2012). Thus, determining whether LEC mediated top-down modulation of aPCX cortical activity (in addition to behavioral acuity) is dependent on task difficulty will require future work. Nonetheless, the current results demonstrate the robust nature of this feedback.

Finally, although the present data are interpreted in the context of LEC feedback to other olfactory areas, we cannot rule out that entorhinal cortex itself is the site of computations required for high acuity olfactory perception. Previous data have in fact demonstrated that single-units in the LEC show more narrow odor tuning properties than those in PCX (Xu and Wilson, 2012), and as mentioned above entorhinal cortical volume correlates with olfactory perception (Segura et al., 2013). Further work will be required to isolate the relative contributions of the PCX, the LEC and their interactions in processes necessary for fine odor acuity.

In summary, the entorhinal cortex serves not only as a gateway for olfactory information to enter the hippocampal formation, but also provides a powerful top-down feedback that modulates PCX function and behavioral olfactory acuity for familiar odors. This suggests that disruption of entorhinal cortical function in disease states may impair olfactory perception. The early appearance of olfactory deficits in Alzheimer's disease, before major cognitive impairment, may in part reflect the early emergence of neuropathology in the transentorhinal cortex (Braak and Braak, 1992; Braak et al., 2011) and a consequent loss of top-down control over more peripheral regions of the olfactory pathway.

\section{References}

Abraham NM, Spors H, Carleton A, Margrie TW, Kuner T, Schaefer AT (2004) Maintaining accuracy at the expense of speed: stimulus similarity defines odor discrimination time in mice. Neuron 44:865-876. CrossRef Medline
Agster KL, Burwell RD (2009) Cortical efferents of the perirhinal, postrhinal, and entorhinal cortices of the rat. Hippocampus 19:1159-1186. CrossRef Medline

Barnes DC, Hofacer RD, Zaman AR, Rennaker RL, Wilson DA (2008) Olfactory perceptual stability and discrimination. Nat Neurosci 11: 1378-1380. CrossRef Medline

Baxter MG (2009) Involvement of medial temporal lobe structures in memory and perception. Neuron 61:667-677. CrossRef Medline

Berens P (2009) CircStat: a MATLAB toolbox for circular statistics. J Stat Soft 31:1-21.

Bernabeu R, Thiriet N, Zwiller J, Di Scala G (2006) Lesion of the lateral entorhinal cortex amplifies odor-induced expression of c-fos, junB, and zif $268 \mathrm{mRNA}$ in rat brain. Synapse 59:135-143. CrossRef Medline

Best AR, Thompson JV, Fletcher ML, Wilson DA (2005) Cortical metabotropic glutamate receptors contribute to habituation of a simple odorevoked behavior. J Neurosci 25:2513-2517. CrossRef Medline

Boeijinga PH, Lopes da Silva FH (1989) Modulations of EEG activity in the entorhinal cortex and forebrain olfactory areas during odour sampling. Brain Res 478:257-268. CrossRef Medline

Braak H, Braak E (1992) The human entorhinal cortex: normal morphology and lamina-specific pathology in various diseases. Neurosci Res 15:6-31. CrossRef Medline

Braak H, Thal DR, Ghebremedhin E, Del Tredici K (2011) Stages of the pathologic process in Alzheimer disease: age categories from 1 to 100 years. J Neuropathol Exp Neurol 70:960-969. CrossRef Medline

Buonviso N, Amat C, Litaudon P, Roux S, Royet JP, Farget V, Sicard G (2003) Rhythm sequence through the olfactory bulb layers during the time window of a respiratory cycle. Eur J Neurosci 17:1811-1819. CrossRef Medline

Burwell RD, Amaral DG (1998) Cortical afferents of the perirhinal, postrhinal, and entorhinal cortices of the rat. J Comp Neurol 398:179-205. CrossRef Medline

Buzsaki G (2006) Rhythms of the brain. New York: Oxford UP.

Canto CB, Wouterlood FG, Witter MP (2008) What does the anatomical organization of the entorhinal cortex tell us? Neural Plast 2008:381243. CrossRef Medline

Cenier T, David F, Litaudon P, Garcia S, Amat C, Buonviso N (2009) Respiration-gated formation of gamma and beta neural assemblies in the mammalian olfactory bulb. Eur J Neurosci 29:921-930. CrossRef Medline

Chabaud P, Ravel N, Wilson DA, Mouly AM, Vigouroux M, Farget V, Gervais R (2000) Exposure to behaviourally relevant odour reveals differential characteristics in rat central olfactory pathways as studied through oscillatory activities. Chem Senses 25:561-573. CrossRef Medline

Chapuis J, Wilson DA (2012) Bidirectional plasticity of cortical pattern recognition and behavioral sensory acuity. Nat Neurosci 15:155-161. CrossRef Medline

Chen CF, Barnes DC, Wilson DA (2011) Generalized versus stimulusspecific learned fear differentially modifies stimulus encoding in primary sensory cortex of awake rats. J Neurophysiol 106:3136-3144. CrossRef Medline

Cleland TA, Linster C (2003) Central olfactory structures. In: Handbook of olfaction and gustation, Ed 2 (Doty RL, ed), pp 165-180. New York: Marcel Dekker.

Deshmukh SS, Knierim JJ (2011) Representation of non-spatial and spatial information in the lateral entorhinal cortex. Front Behav Neurosci 5:69. CrossRef Medline

Devanand DP, Michaels-Marston KS, Liu X, Pelton GH, Padilla M, Marder K, Bell K, Stern Y, Mayeux R (2000) Olfactory deficits in patients with mild cognitive impairment predict Alzheimer's disease at follow-up. Am J Psychiatry 157:1399-1405. CrossRef Medline

Eeckman FH, Freeman WJ (1990) Correlations between unit firing and EEG in the rat olfactory system. Brain Res 528:238-244. CrossRef Medline

Egorov AV, Hamam BN, Fransén E, Hasselmo ME, Alonso AA (2002) Graded persistent activity in entorhinal cortex neurons. Nature 420:173178. CrossRef Medline

Eichenbaum H, Fagan A, Mathews P, Cohen NJ (1988) Hippocampal system dysfunction and odor discrimination learning in rats: impairment or facilitation depending on representational demands. Behav Neurosci 102: 331-339. CrossRef Medline

Engel AK, Fries P (2010) Beta-band oscillations: signalling the status quo? Curr Opin Neurobiol 20:156-165. CrossRef Medline

Engel AK, Fries P, Singer W (2001) Dynamic predictions: oscillations and 
synchrony in top-down processing. Nat Rev Neurosci 2:704-716. CrossRef Medline

Ferry B, Oberling P, Jarrard LE, Di Scala G (1996) Facilitation of conditioned odor aversion by entorhinal cortex lesions in the rat. Behav Neurosci 110:443-450. CrossRef Medline

Haberly LB, Price JL (1978) Association and commissural fiber systems of the olfactory cortex of the rat: I. systems originating in the piriform cortex and adjacent areas. J Comp Neurol 178:711-740. CrossRef Medline

Hasselmo ME, Stern CE (2006) Mechanisms underlying working memory for novel information. Trends Cogn Sci 10:487-493. CrossRef Medline

Insausti R, Herrero MT, Witter MP (1997) Entorhinal cortex of the rat: cytoarchitectonic subdivisions and the origin and distribution of cortical efferents. Hippocampus 7:146-183. Medline

Jensen O, Kaiser J, Lachaux JP (2007) Human gamma-frequency oscillations associated with attention and memory. Trends Neurosci 30: 317-324. CrossRef Medline

Kay LM, Beshel J (2010) A beta oscillation network in the rat olfactory system during a 2-alternative choice odor discrimination task. J Neurophysiol 104:829-839. CrossRef Medline

Kay LM, Freeman WJ (1998) Bidirectional processing in the olfactorylimbic axis during olfactory behavior. Behav Neurosci 112:541-553. CrossRef Medline

Kay LM, Lancaster LR, Freeman WJ (1996) Reafference and attractors in the olfactory system during odor recognition. Int J Neural Syst 7:489-495. CrossRef Medline

Kay LM, Beshel J, Brea J, Martin C, Rojas-Líbano D, Kopell N (2009) Olfactory oscillations: the what, how and what for. Trends Neurosci 32:207-214. CrossRef Medline

Kerr KM, Agster KL, Furtak SC, Burwell RD (2007) Functional neuroanatomy of the parahippocampal region: the lateral and medial entorhinal areas. Hippocampus 17:697-708. CrossRef Medline

Ketchum KL, Haberly LB (1993a) Synaptic events that generate fast oscillations in piriform cortex. J Neurosci 13:3980-3985. Medline

Ketchum KL, Haberly LB (1993b) Membrane currents evoked by afferent fiber stimulation in rat piriform cortex: II. Analysis with a system model. J Neurophysiol 69:261-281. Medline

Kjelvik G, Evensmoen HR, Brezova V, Håberg AK (2012) The human brain representation of odor identification. J Neurophysiol 108:645-657. CrossRef Medline

Litaudon P, Garcia S, Buonviso N (2008) Strong coupling between pyramidal cell activity and network oscillations in the olfactory cortex. Neuroscience 156:781-787. CrossRef Medline

Lovitz AM, Sloan AM, Rennaker RL, Wilson DA (2012) Complex mixture discrimination and the role of contaminants. Chem Senses 37:533-540. CrossRef Medline

Luna VM, Morozov A (2012) Input-specific excitation of olfactory cortex microcircuits. Front Neural Circuits 6:69. CrossRef Medline

Luskin MB, Price JL (1983) The laminar distribution of intracortical fibers originating in the olfactory cortex of the rat. J Comp Neurol 216:292-302. CrossRef Medline

Martin C, Beshel J, Kay LM (2007) An olfacto-hippocampal network is dynamically involved in odor-discrimination learning. J Neurophysiol 98: 2196-2205. CrossRef Medline

Mesholam RI, Moberg PJ, Mahr RN, Doty RL (1998) Olfaction in neurodegenerative disease. Arch Neurol 55:84-90. CrossRef Medline
Mouly AM, Di Scala G (2006) Entorhinal cortex stimulation modulates amygdala and piriform cortex responses to olfactory bulb inputs in the rat. Neuroscience 137:1131-1141. CrossRef Medline

Murphy C (1999) Loss of olfactory function in dementing disease. Physiol Behav 66:177-182. CrossRef Medline

Neville KR, Haberly LB (2003) Beta and gamma oscillations in the olfactory system of the urethane-anesthetized rat. J Neurophysiol 90:3921-3930. CrossRef Medline

Osakada F, Mori T, Cetin AH, Marshel JH, Virgen B, Callaway EM (2011) New rabies virus variants for monitoring and manipulating activity and gene expression in defined neural circuits. Neuron 71:617-631. CrossRef Medline

Otto T, Garruto D (1997) Rhinal cortex lesions impair simultaneous olfactory discrimination learning in rats. Behav Neurosci 111:1146-1150. CrossRef Medline

Otto T, Schottler F, Staubli U, Eichenbaum H, Lynch G (1991) Hippocampus and olfactory discrimination learning: effects of entorhinal cortex lesions on olfactory learning and memory in a successive-cue, go-no-go task. Behav Neurosci 105:111-119. CrossRef Medline

Paxinos G, Watson C (2009) The rat brain in stereotaxic coordinates, Ed 6. San Diego: Academic.

Poo C, Isaacson JS (2009) Odor representations in olfactory cortex: "sparse" coding, global inhibition, and oscillations. Neuron 62:850-861. CrossRef Medline

Rinberg D, Koulakov A, Gelperin A (2006) Speed-accuracy tradeoff in olfaction. Neuron 51:351-358. CrossRef Medline

Schoenbaum G, Eichenbaum H (1995) Information coding in the rodent prefrontal cortex: I. single-neuron activity in orbitofrontal cortex compared with that in pyriform cortex. J Neurophysiol 74:733-750. Medline

Segura B, Baggio HC, Solana E, Palacios EM, Vendrell P, Bargalló N, Junqué C (2013) Neuroanatomical correlates of olfactory loss in normal aged subjects. Behav Brain Res 246:148-153. CrossRef Medline

Smith JJ, Shionoya K, Sullivan RM, Wilson DA (2009) Auditory stimulation dishabituates olfactory responses via noradrenergic cortical modulation. Neural Plast 2009:754014. CrossRef Medline

Stranahan AM, Mattson MP (2010) Selective vulnerability of neurons in layer II of the entorhinal cortex during aging and Alzheimer's disease. Neural Plast 2010:108190. CrossRef Medline

Suzuki WA (2009) Perception and the medial temporal lobe: evaluating the current evidence. Neuron 61:657-666. CrossRef Medline

Uchida N, Kepecs A, Mainen ZF (2006) Seeing at a glance, smelling in a whiff: rapid forms of perceptual decision making. Nat Rev Neurosci 7:485-491. CrossRef Medline

Wirth S, Ferry B, Di Scala G (1998) Facilitation of olfactory recognition by lateral entorhinal cortex lesion in rats. Behav Brain Res 91:49-59. CrossRef Medline

$\mathrm{Xu}$ W, Wilson DA (2012) Odor-evoked activity in the mouse lateral entorhinal cortex. Neuroscience 223:12-20. CrossRef Medline

Zion Golumbic EM, Ding N, Bickel S, Lakatos P, Schevon CA, McKhann GM, Goodman RR, Emerson R, Mehta AD, Simon JZ, Poeppel D, Schroeder CE (2013) Mechanisms underlying selective neuronal tracking of attended speech at a "cocktail party." Neuron 77:980-991. CrossRef Medline 